\title{
8-Core Prostate Biopsy
}

National Cancer Institute

\section{Source}

National Cancer Institute. 8-Core Prostate Biopsy. NCI Thesaurus. Code C142181.

A prostate biopsy collection protocol that consists of sextant cores plus 2 lateral peripheral zone cores. 